\title{
Hepatik kitle ile prezente olan, ERCP ile ekstraksiyonu yapılan Fasciola hepatica: olgu sunumu ve literatürün gözden geçirilmesi
}

Presentation with hepatic mass and ERCP extraction of Fasciola hepatica: A case report and review of the literature

Ahmet UYANIKOĞLU1 ${ }^{1}$, Kadir DEMIR², Filiz AKYÜZ², Fatih ERMIŞ3, Fatih BEŞIŞIK², Güngör BOZTAŞ²

${ }^{1}$ Harran Üniversitesi, Tip Fakültesi, Gastroenteroloji Bilim Dal, Sanlurfa

${ }^{2}$ Istanbul Universitesi, Istanbul Tip Fakültesi, Gastroenteroloji Bilim Dall, Sanlıurfa

${ }^{3}$ Düzce Üniversitesi, Tip Fakültesi, Gastroenteroloji Bilim Dal, Düzce

Fasciola hepatica infeksiyonu ülkemizin bazı bölgelerinde endemik olarak rastlanan bir karaciğer trematodudur. Klinik bulgular nonspesifik olup; karın ağrisl, sağ üst kadranda hassasiyet şeklinde olabilir. Laboratuvarda eozinofili, karaciğer enzimlerinin yükselmesi, pozitif seroloji görülür. Görüntüleme yöntemlerinde karaciğerde çok sayıda nodüller ve safra yollarında dilatasyon görülür. Triclabendazol hepatik ve biliyer fazda etkilidir. Endoskopik retrograd kolanjiopankreatografi ile canlı Fasciola hepaticalarn biliyer kanaldan uzaklaștırılması ile de tedavi edilir. Burada karaciğerde kitle nedeniyle tetkik edilen, safra yollarnda dilatasyona neden olan ve endoskopik retrograd kolanjiopankreatografi ile tedavi edilen fasciola hepaticalı genç bayan olgusu sunulmuştur.

Anahtar kelimeler: Fasciola hepatica, eozinofili

\section{GİRISS}

Fasciola hepatica (FH) zoonotik, parazitik infeksiyonu olup dünyada yaygın olarak Güney ve Orta Amerika, Afrika, Asya, Ortadoğu, Avusturalya ve Çin'de görülür. Güneydoğu Akdeniz ve ülkemizin bazı bölgelerinde endemik olarak rastlanan bir karaciğer trematodudur. Koyun ve sığırları infekte etmekle birlikte, bazen insanlarda tesadüfi konakçı olabilmektedir. FH'nın neden olduğu karaciğer infeksiyonuna fasiliozis denilir (1-5).

Klinik belirtileri nonspesifiktir. Karın ağrısı, ateş, eozinofili, karaciğer enzimlerinin yükselmesi en yaygın semptom ve bulgulardır. FH serolojik testleri tüm hastalarda pozitiftir $(1,2)$. Ultrasonografide (USG) karaciğerde multipl hipoekoik nodüller ve parankimal heterojenite görülür (6). Hepatik fazda bilgisayarlı tomografi (BT) ve magnetik rezonans görüntülemede (MRG) mikroabselere benzer multipl nodüler lezyonlar, coğrafi görünüm en önemli bulgularıdır. Biliyer fazda ise endoskopik retrograd kolanjiopankreatografi (ERCP)'de distal koledokta küçük lineer dolum defektleri en önemli bulgusudur $(7,8)$.

Karaciğerde kitle nedeniyle tetkik edilen hastada tesbit edilen, safra yollarında dilatasyona neden olduğu için biliyer fazda ERCP yapılan FH vakası sunulmuştur.
Fasciola hepatica is a liver trematode that is endemic in some parts of Turkey. Clinical findings are nonspecific, such as abdominal pain and right upper quadrant tenderness. Eosinophilia, elevated liver enzymes and positive serology can be detected in laboratory investigations, while multiple nodules in the liver and dilated bile ducts can be seen in imaging modalities. Triclabendazole is effective in the hepatic and biliary phases. Fasciola hepatica is also treated with endoscopic retrograde cholangiopancreatography by biliary duct removal. Herein, we present a young woman who was evaluated with a mass in the liver and biliary tract dilatation caused by Fasciola hepatica and who was treated with endoscopic retrograde cholangiopancreatography.

Key words: Fasciola hepatica, eosinophilia

\section{OLGU SUNUMU}

Hayvancılıkla uğraşılan bir bölgede oturan 34 yaşında kadın hastanın 1 yıldır devam eden iştahsızlık, sağ üst kadran ağrısı, bulantı-kusma, 6 kilo zayıflama şikayetleri vardı. Hastanın öz geçmişinde apendektomi, fizik muayenesinde sağ üst kadranda derin palpasyonla hassasiyet dışında özellik yoktu. Başlangıçta başka bir merkezde takip edilen hastanın laboratuvarında transaminazlar 2 kat yüksek, sedimantasyon $70 \mathrm{~mm} / \mathrm{saat}$ ve eozinofili saptanmıştı. Batın USG'sinde karaciğer heterojen, MRG'sinde ise karaciğer parankiminde yer yer hiperintens coğrafi dağılımlı alanlar izlenmişti. Duodenal aspiratta ve gaitada FH yumurtası görülen, FH ELISA serolojik testi pozitif saptanan hastaya triclabendasole $10 \mathrm{mg} / \mathrm{kg} 2$ gün tedavisi uygulanmıştı. Şikayetleri kısmen devam eden hastada MR kolanjiyogram çekilmiş ve safra yolları dilate saptanması üzerine ERCP yapılması için hastanemize sevk edilmişti. ERCP için yatırılan hastanın kontrol hemogramında hafif eozinofili saptandı, biyokimya tetkiklerinde özellik yoktu. Yeni çekilen BT'si geçirilmiş kolanjitle uyumlu olarak rapor edildi ve karaciğerde düzensiz lokal coğrafi görünüm dikkat çekti (Resim 1). MR kolanjiyogramda görülen doluş defektleri ERCP'de saptanmadi. Hastaya sfinkterotomi yapilarak koledok balonla süpürüldü. Safra yollarından ölü Fasciola 


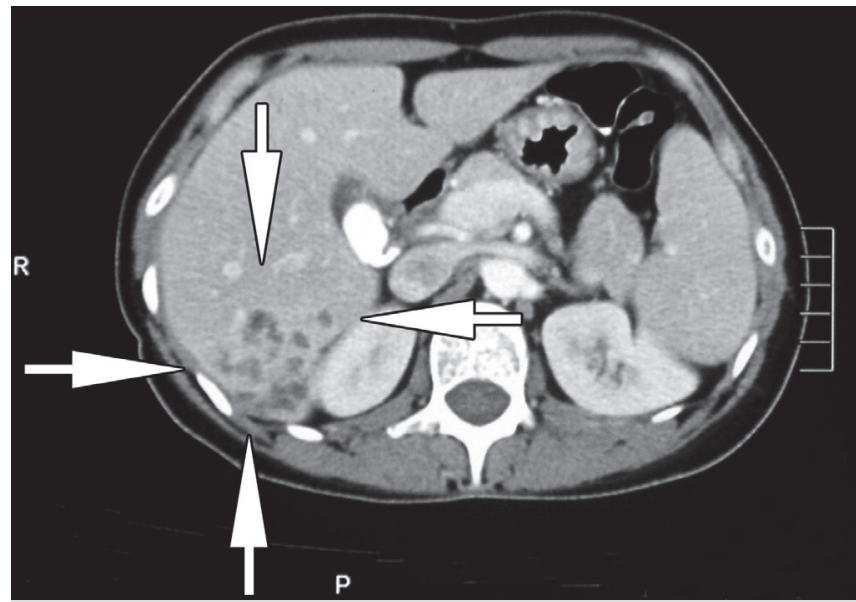

Resim 1. Bilgisayarlı tomografide karaciğerde, Fasciola hepatica'nın neden olduğu lokal düzensiz coğrafi görünüm.

parçaları ve debris olduğu düşünülen materyaller temizlendi. Hasta poliklinikten takip edilmek üzere taburcu edildi.

\section{TARTISMA}

Fasciola hepatica infeksiyonu endemik bölgeler dışında nadir görülür. Türkiye'de sık olduğu bildirilmiştir (9). Dünyada Güneydoğu Akdeniz bölgesi endemik bölgelerdendir. Ülkemizde özellikle hayvancılıkla uğraşılan bölgelerde, Akdeniz, Güneydoğu ve Doğu Anadolu bölgelerinde sıktır. Mersin yöresinde yapılan bir çalışmada seropozitiflik oranı \%0,79 olarak bildirilmiştir. Mersin bölgesinin hipoendemik olduğu, aile hikayesi olanlarla olmayanlar arasında seroprevalans arasında fark olmadığı bildirilmiştir $(1,9,10)$. Tümör şüphesi ile tetkik edilmiş hastanın hayvancılıkla uğraşılan bir bölgede yaşıyor olması FH tanısı açısından önemli olmuştur.

Klasik FH tutulum yeri karaciğer olup hepatik ve biliyer fazda farklı görünüm ve prezantasyona rastlanır. Akut pankreatite neden olabilir. 30 hastanın incelendiği bir seride hastaların 24'ü kadın, yaş ortalaması 42,6, 22'si (\%73) hepatik fazda, 5 tanesi biliyer fazda, 3 tanesi akut pankreatit ile saptanmıştır (7). FH hastaları pankreasta kitle, asit, asemptomatik hastada laparoskopik karaciğer biyopsisi ile ve kraniyal tutulum gibi değişik klinik prezantasyonlarla da görülebilmektedir (11-15). Hastamız 34 yaşında, kadın idi, başlangıçta hepatik fazda yakalanmış, medikal tedavi verilmiş; bize müracaat ettiginde ise biliyer fazda idi ve hastaya bu safhada ERCP yapılarak safra yolları temizlendi.

Hastalarda semptom ve bulgular nonspesifiktir. Karın ağrısı ve sağ üst kadranda hassasiyet en sik semptom ve bulgudur. Diare, bulantı-kusma, yorgunluk, iştahsızlık, kilo kaybı, kaşıntı, gece terlemesi, öksürük, pika, anemi, lökositoz, serum IgE ve sedimantasyon yüksekliği görülebilen diğer semptom ve bulgulardır $(1,3,7,16)$. Hastamızda iştahsızlık, sağ üst kadranda ağrı, bulantı-kusma ve 1 yılda 6 kilo zayıflama şikayetleri mevcuttu ve bu şikayetler nonspesifikti. Eozinofili ve karaciğer enzimlerinde yükseklik en sık saptanan laboratuvar bulgulardır $(7,17,18)$. Eozinofilik lökositozun lösemiyi taklit decek düzeylere kadar yükselebileceği bildirilmiştir (19). Hastada başlangıçta 2 katı bulan transaminaz yüksekliği ve eozinofili tanı açısından uyarıcı olmuştur.

Tanı için tüm hastalarda serolojik testlerin pozitif olduğu bildirilmiştir (2). FH'li ve sağlıklı kişilerde Echinococcus granulosis indirekt immünfloresans testinin pozitif saptanabildiği bildirilmiştir (20). FH indirekt serum hemaglütinasyon, indirekt immünfloresans, ELISA yöntemleri ile araştırılabilir (1, 17, 21). Duodenal aspiratta ve gaitada FH yumurtası saptanması, her hastada mümkün olmamaktadır (22). Hastamızda ilk müracaat ettiği merkezde tanıda serolojik testi pozitif, duodenal aspiratta ve gaitada FH yumurtası saptanmıştı.

Fizik muayene ve laboratuvar testlerinden sonra ilk yapılacak tanı testi abdominal USG'dir. Başlangıç döneminde USG bulguları nonspesifiktir (8). USG'de multipl hipoekoik nodül ve parankimde heterojenite görülür (6). Kontrastlı USG hepatik fasioliaziste tanı ve takipte daha yararlı olabilir (23). BT'de subkapsüler, prebiliyer veya periportal lineer veya dallanma gösteren, mikroabselere benzer hipodens nodüller görülür $(6,24)$, MRG karaciğer parankimal tutulumu ve hemorajik lezyonları BT'den daha iyi gösterir. Biliyer fazda safra yollarindaki dilatasyonu göstermede USG ve MR kolanjiyografi daha kullanışlıdır. Görüntüleme yöntemlerinin kombine kuulanılmasının ve ELISA ile FH konfirmasyonunun erken tanı için yardımcı olabileceği bildirilmiştir (8). Hastada USG'de heterojenite, MRG'de ve BT'de karaciğer parankiminde yer yer hiperintens coğrafi dağılımlı alanlar izlenmiştir.

Triclabendasole $10 \mathrm{mg} / \mathrm{kg}$ tek doz 2-4 hafta sonra tekrar $(1,16), 2$ gün triclabendasole $10 \mathrm{mg} / \mathrm{kg}$ (3), bithionol (2), albendazole (11) medikal tedavide kullanılan ilaçlardır. Hastamızda triclabendasole $10 \mathrm{mg} / \mathrm{kg}$, 2 gün tedavi uygulanmıştır. Medikal tedavi sonrası hastanın karın ağrısı şikayeti devam etmiş, karaciğer enzimleri normal sınıra gerilemiştir. Eozinofili gerilemesine rağmen ERCP için müracaat ettiği dönemde normal sınırlarda değildi.

Biliyer fazda, kolestaza neden olduğunda tanı ve tedavide ERCP kolayca uygulanmaktadır. Ortak biliyer kanal obstrüksiyonuna bağlı sarllık nadir görülen bir durumdur. USG ve BT biliyer dilatasyonu gösterir, ancak ayıııı tanı imkanı sağlamaz. ERCP FH varlığını gösterir $(25,26)$. ERCP'de distal koledokta küçük lineer dolum defekti ana bulgudur. Hepatik fazda triclabendazol, biliyer fazda triclabendazol ve canlı FH'nın ERCP ile biliyer kanaldan uzaklaştırılması esastır (7). Fasioliazisin neden olduğu akut kolanjitin cerrahi olarak tanı konulduğu ve tedavi edilebildiği, tedavide kolesistektomi, koledokotomi, T-tüp drenaj uygulandığı bildirilmiştir (27). 
Hastaya başlangıçta medikal tedavi verilmiş, tedaviden kısmen yararlanmış, ancak safra yollarında FH saptanınca ERCP ile safra yolları temizlenmiştir.

Fasciola hepatica infeksiyonu özellikle endemik bölgelerde yaşayan, eozinofilisi olan, görüntüleme yöntemlerinde kara-

\section{KAYNAKLAR}

1. Hakyemez IN, Aktaş G, Savli H, et al. A Fascioliasis case: a not rare cause of hypereosinophilia in developing countries, present in developed too. Mediterr J Hematol Infect Dis 2012; 4: e2012029.

2. Aksoy DY, Kerimoğlu U, Oto A, et al. Fasciola hepatica infection: clinical and computerized tomographic findings of ten patients. Turk J Gastroenterol 2006; 17: 40-5.

3. Trifina E, Spenger J, Zandieh S, et al. Multiple liver lesions accompanied by eosinophilia - a case report of fascioliosis. Wien Med Wochenschr 2011; 161: 448-54

4. Noyer CM, Coyle CM, Werner C, et al. Hypereosinophilia and liver mass in an immigrant. Am J Trop Med Hyg 2002; 66: 774-6.

5. Periago MV, Valero MA, El Sayed M, et al. First phenotypic description of Fasciola hepatica/Fasciola gigantica intermediate forms from the human endemic area of the Nile Delta, Egypt. Infect Genet Evol 2008; 8: 51-8.

6. Koç Z, Ulusan S, Tokmak N. Hepatobiliary fascioliasis: imaging characteristics with a new finding. Diagn Interv Radiol 2009; 15: 247-51.

7. Kaya M, Beștas R, Cetin S. Clinical presentation and management of Fasciola hepatica infection: single-center experience. World J Gastroenterol 2011; 17: 4899-904

8. Dusak A, Onur MR, Cicek M, et al. Radiological imaging features of Fasciola hepatica infection - a pictorial review. J Clin Imaging Sci 2012; 2: 2 .

9. Sakru N, Korkmaz M, Demirci M, et al. Fasciola hepatica infection in echinococcosis suspected cases. Turkiye Parazitol Derg 2011; 35: 77-80.

10. Ozturhan H, Emekdaş G, Sezgin O, et al. Seroepidemiology of Fasciola hepatica in Mersin province and surrounding towns and the role of family history of the Fascioliasis in the transmission of the parasite. Turk J Gastroenterol 2009; 20: 198-203.

11. Oncu K, Yazgan Y, Kaplan M, et al. An extremely uncommon case of parasitic infection presenting as eosinophilic ascites in a young patient. Case Rep Gastroenterol 2011; 5: 139-43.

12. Adachi S, Kotani K, Shimizu T, et al. Asymptomatic fascioliasis. Intern Med 2005; 44: 1013-5.

13. Lee OJ, Kim TH. Indirect evidence of ectopic pancreatic fascioliasis in a human. J Gastroenterol Hepatol 2006; 21: 1631-3.

14. Bengisun U, Ozbas S, Sarioglu U. Fascioliasis observed during laparoscopic cholecystectomy. Langenbecks Arch Surg 1999; 384: 84-7. ciğerde coğrafi görünüm, heterojenite, nodüler görünüm ve safra yollarında dilatasyon saptanan hastalarda ayırıcı tanıda akla gelmelidir. Tedavide hepatik fazda triclabendasole, biliyer fazda triclabendasole ve fasciola hepaticalarn ERCP ile biliyer kanaldan uzaklaştırılması esastır.

15. Zhou L, Luo L, You C, et al. Multiple brain hemorrhages and hematomas associated with ectopic fascioliasis in brain and eye. Surg Neurol 2008; 69: $516-21$.

16. Deveci U, Oztürk T, Ustün C. A case of radiologically diagnosed pediatric Fasciola hepatica. Turkiye Parazitol Derg 2011; 35: 117-9.

17. Christmann M, Henrich R, Mayer G, Ell C. Infection with fasciola hepatica causing elevated liver-enzyme results and eosinophilia - serologic and endoscopic diagnosis and therapy. Z Gastroenterol 2002; 40: 801-6.

18. Fica A, Dabanch J, Farias C, et al. Acute fascioliasis--clinical and epidemiological features of four patients in Chile. Clin Microbiol Infect 2012; 18: 91-6.

19. Gökçe M, Sahiner U, Unal S, et al. An unexpected parasitic cause of hypereosinophilia: fascioliasis. Turk J Pediatr 2011; 53: 111-3.

20. Kaya M, Beştaş R, Girgin S, et al. Increased anti-Echinococcus granulosus antibody positivity in Fasciola hepatica infection. Turk J Gastroenterol 2012; 23: 339-43.

21. Figueroa-Santiago O, Delgado B, Espino AM. Fasciola hepatica saposinlike protein-2-based ELISA for the serodiagnosis of chronic human fascioliasis. Diagn Microbiol Infect Dis 2011; 70: 355-61.

22. Kodama K, Ohnishi H, Matsuo T, Matsumura T. Three cases of human fascioliasis. Kansenshogaku Zasshi 1991; 62: 1620-4.

23. Weiss D, Marti G, Mouton W, et al. Infection with fasciola hepatica-a case series. Ultraschall Med 2010; 31: 175-81.

24. Cantisani V, Cantisani C, Mortelé K, et al. Diagnostic imaging in the study of human hepatobiliary fascioliasis. Radiol Med 2010; 115: 83-92.

25. Gulsen MT, Savas MC, Koruk M, et al. Fascioliasis: a report of five cases presenting with common bile duct obstruction. Neth J Med 2006; 64: $17-9$.

26. Ezzat RF, Karboli TA, Kasnazani KA, Hamawandi AM. Endoscopic management of biliary fascioliasis: a case report. J Med Case Rep 2010; 4: 83.

27. Miman Ö, Özkeçecı T, Okur N, et al. A rare cause of obstructive jaundice: fascioliasis. Turkiye Parazitol Derg 2010; 34: 190-92. 